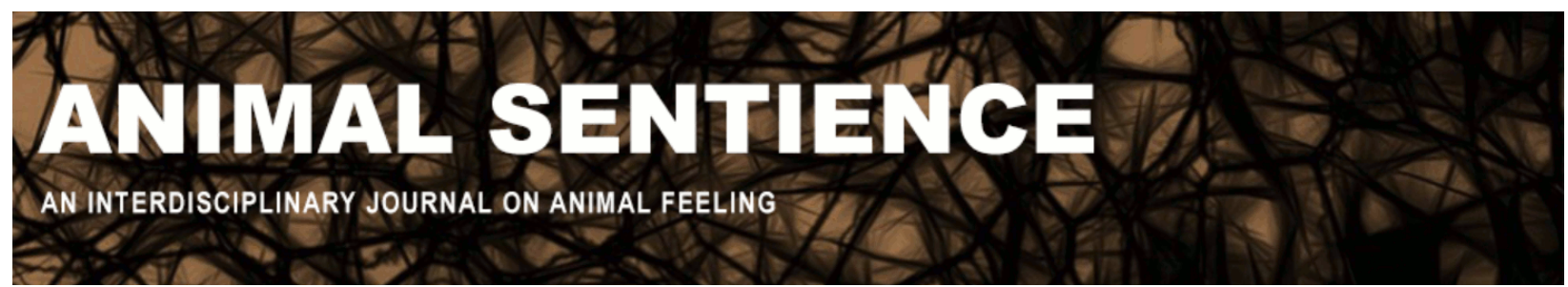

Birch, Jonathan (2018) On crabs and statistics. Animal Sentience 16(23)

DOI: $10.51291 / 2377-7478.1377$

Date of submission: 2018-11-14

Date of acceptance: 2018-11-19

(c) (i)

This article has appeared in the journal Animal

Sentience, a peer-reviewed journal on animal

cognition and feeling. It has been made open access,

free for all, by WellBeing International and deposited

in the WBI Studies Repository. For more information,

please contact

wbisr-info@wellbeingintl.org.

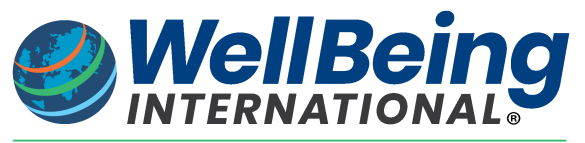

SOLUTIONS FOR PEOPLE, ANIMALS AND ENVIRONMENT 


\title{
On crabs and statistics
}

Response to Commentary on Birch on Precautionary Principle

\author{
Jonathan Birch \\ Department of Philosophy, Logic and Scientific Method \\ London School of Economics and Political Science
}

\begin{abstract}
I respond to commentaries by Elwood and Seth \& Dienes and to a recent critique by Diggles, discussing the link between avoidance learning and sentience, the relevance of the clash between frequentist and Bayesian statistics, the risks to decapod welfare in aquaculture, and the broader concerns one may have about a "precautionary" approach to protecting invertebrates.
\end{abstract}

Ionathan Birch is Associate Professor at the London School of Economics and Political Science, specializing in the philosophy of biology. His book The Philosophy of Social Evolution was published by Oxford University Press in 2017. Website

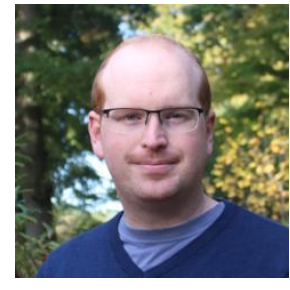

The commentaries on my target article on animal sentience and the precautionary principle (Birch 2017a) by Elwood and Seth \& Dienes - not yet published at the time of my of Response to the first round of commentaries (Birch 2017b) — are excellent contributions to the debate. Meanwhile, in another journal, a substantial critique of some of my arguments, and of the evidence regarding sentience in decapods, has recently appeared (Diggles 2018). Here I respond to Elwood, Seth \& Dienes as well as Diggles. I discuss the link between avoidance learning and sentience, the relevance of the clash between frequentist and Bayesian statistics, the risks to decapod welfare in aquaculture, and the broader concerns one may have about a "precautionary" approach to protecting invertebrates.

\section{Which forms of avoidance learning are sentience-linked?}

Elwood raises several interesting issues. What particularly caught my attention is his distinction between swift and slow avoidance learning: Whole crabs learn fast to avoid electric shocks (sometimes requiring only two trials), whereas decerebrate crabs learn slowly (requiring over 5,000 trials), leading Elwood to suggest, plausibly, that the former ability is a credible positive indicator of sentience whereas the latter is not.

One way or another, we do, I think, have to draw a distinction between forms of avoidance learning that are credible indicators of sentience and forms that are not. Nematode worms can do avoidance learning with 302 neurons (Ha et al. 2010). We can't be sure they are not sentient (and I have never claimed they are not). But the possibility of avoidance learning in extremely simple nervous systems should give us pause on the question of whether avoidance learning is a credible indicator of sentience. 
The drawback of insisting on fast avoidance learning is of course that speed is a matter of degree, and it is not clear there is any way to draw a non-arbitrary line between forms of learning on the basis of speed alone. The difference is quantitative, but the difference between the presence or absence of sentience is qualitative (even if sentience, when present, can vary along multiple dimensions, as suggested in Birch 2018). Perhaps a better approach is to look for qualitative differences between forms of avoidance learning.

Bronfman et al. (2016) distinguish between limited and unlimited associative learning, taking only the latter to be a credible indicator of sentience. What is "unlimited" associative learning? It is associative learning in which compound stimuli (consisting of packages of colours, shapes, textures, smells, etc.) can be associated with complex action sequences and with other compound stimuli, with the possibility of higher-order conditioning. This is contrasted with "limited" associative learning, in which the conditioned stimulus must be simple (a single sensory stimulus) and only first-order conditioning is possible. Learning in nematodes and decerebrate crabs may well be "limited" in this sense, whereas learning in healthy arthropods, cephalopods and vertebrates seems substantially less limited.

Another proposal is that of Allen $(2004,2013)$, who highlights the special importance of trace conditioning as opposed to other kinds of conditioning. Trace conditioning is a variant of classical conditioning in which the conditioned and unconditioned stimuli are separated in time: for example, a light flash might be followed, a few seconds later, by a blast of air. Trace conditioning requires an ability to keep track of temporal relations between stimuli. This "keeping track" seems to involve consciousness in humans, even though it could (of course) conceivably occur without it (Clark and Squire 1998). I have not come across any studies showing trace conditioning in crabs, but it has been found in rainbow trout (Nordgreen et al. 2010), fruit flies (Dylla et al. 2013) and honey bees (Szyszka et al. 2011).

I suspect the distinction between whole-organism and part-specific behaviours is also relevant. Learned leg withdrawal in the shore crab may be possible without centralized processing, but it is not a behaviour of the whole organism. By contrast, choosing a shelter involves the whole organism and requires centralized processing. There is a suggestive analogy with blindsight in humans: blindsight patients can use unconscious information to guide the movement of a limb, but they can't use this information to guide strategic, wholeorganism behaviour (Dretske 2006).

These considerations suggest that avoidance learning, while not a credible indicator of sentience by itself, may become a credible indicator in the presence of one or more additional features. But this matter is far from settled, and I invite further discussion on the question of which forms of avoidance learning are indicative of sentience and why.

\section{Bayes factors or significance levels?}

Seth \& Dienes connect the Animal Sentience Precautionary Principle (ASPP) to the longrunning clash between frequentist and Bayesian approaches in statistics. This leads to an interesting question: does a framework for converting scientific evidence into a policy response, such as ASPP, really need to make any commitments at all regarding statistical methodology?

My proposals included a requirement of "statistically significant evidence" of a credible indicator of sentience but deliberately avoided any specification of the required significance level, since this should be fixed by normal scientific standards. For Seth \& Dienes, 
this minimal requirement is already regrettable, because "statistical significance" implies a commitment to frequentist rather than Bayesian statistics.

Why did I include this requirement? Simply because merely requiring "evidence" would be too weak. It would risk allowing that, if an experiment yields merely anecdotal or extremely weak evidence of a credible indicator, that is already enough to satisfy BAR. So, I needed to say something to characterise experimental evidence that is substantial and deserves to be taken seriously by policymakers, and it was natural here to reach for "statistical significance" as the relevant criterion. There are, however, alternative ways of characterising substantial evidence, and this may also be done using Bayes factors.

I don't have strong feelings on this issue. But one drawback to Bayes factors, given the specific aims of ASPP, is that there is no universal norm in the scientific community as to what the Bayes factor has to be before evidence is deemed substantial. I have come across the proposal that a Bayes factor of at least 3 is necessary for substantial evidence (Jeffreys 1998; Wagenmakers et al. 2011), but I'm not sure how strong a consensus there is on this point. By contrast, there is a consensus norm in relation to frequentism: the (infamous) significance level of 0.05 .

This norm is controversial, and understandably so, but it remains a clear norm for the time being, and a clear norm allows a clear rule for moving from evidence to policy. One challenge for Bayesians is to show how the Bayes factor can take on the social and political (as well as statistical) functions of the significance level: the functions of signalling to journals that a result merits publication, and of signalling to policymakers that a result is substantial and should not be ignored.

\section{Is there really evidence of sentience in decapods?}

Decapod crustaceans are a central case for ASPP, because there is ongoing disagreement as to whether they should be brought within the scope of animal welfare law. This is exactly the sort of problem ASPP is intended to help us with. If it does not help, then it is not delivering what it is supposed to deliver.

Because of this, it is important for me to confront the sceptical arguments of Diggles (2018), recently published in the ICES Journal of Marine Science. Diggles's criticisms fall into three categories: (i) doubts about whether there is any threat of serious negative welfare in decapod aquaculture, even on the assumption that the animals are sentient; (ii) specific concerns about the methodology of Elwood and colleagues' experiments; and (iii) broader concerns about allowing a precautionary principle to set the scope of animal welfare protection. Let us consider each of these categories.

\subsection{Serious risks to welfare}

To motivate the first kind of doubt, Diggles discusses several controversial practices used in decapod aquaculture for research purposes, including eyestalk ablation, and argues that these practices do not create a risk of serious negative welfare. If this is right, then precautionary reasoning does not apply, because there is no risk we need to take precautions against.

Diggles's case study pertains to aquaculture in a research facility, not in the context of food production. Even if we grant that there is no serious threat to decapod welfare in research facilities, there would still be very serious concerns about the way they are treated 
in the food industry and the culinary world, where practices such as live carving and live boiling are common (see the commentaries by Elwood and Carder, as well as Elwood 2012; Roth and Grismbø 2016; Birch 2017c).

But I do not think we should grant that there are no serious risks to welfare in research facilities. Eyestalk ablation in particular deserves further scrutiny. As Diggles (2018) describes:

"Eyestalk ablation is a process involving cauterizing or cutting of one of the eyestalks of a mature (>10-month old) broodstock female prawn using flame-sterilized hot forceps or ligation in order to alter the hormonal balance by reducing production of the inhibition hormones, allowing the prawn to undergo the final stages of maturity in captivity." (p.11)

The process is ubiquitous in prawn farming (recall that, in total, around 400 billion decapods are farmed annually) and also in research aquaculture. Diggles notes that the process is known to lead to physiological stress. He also notes evidence that decapods have heatresponsive nociceptors that would be activated by a prolonged exposure ( $>2 \mathrm{~s})$ to the forceps, but which might not be activated by a shorter exposure. His response is that the process is normally rapid $(<2 \mathrm{~s})$ and that "while eyestalk ablation procedures lasting $>2 \mathrm{~s}$ may induce nociception (Puri and Faulkes 2015) and be stressful, nociception does not necessarily lead to pain, and stress does not equal pain" (Diggles 2018, p. 11).

The problem is that, in the present context, it begs the question to appeal to the absence of a necessary connection between nociception and pain (or, more generally, aversive experiences), or between physiological stress and the subjective experience of stress. At issue here is the question of whether there is a serious risk to welfare that might justify precautionary measures in the absence of conclusive evidence of sentience. But all Diggles does is point to the absence of conclusive evidence. He does not establish that there is no serious risk to welfare. Indeed, everything he says about eyestalk ablation supports the idea this practice does pose a serious risk: if nociceptive and stress responses are activated in at least some cases, then there is a serious risk that an aversive experience is felt. We would only be entitled to dismiss this possibility if we were entitled to dismiss the possibility of decapod sentience, and we are not.

\subsection{The methodology of electric shock experiments}

The case for extending welfare protection to decapod crustaceans as a precautionary measure rests heavily on experiments by Elwood and colleagues. In many of these experiments, the noxious stimulus is an electric shock. Diggles questions whether electric shocks can be shown to elicit a nociceptive response in crabs. Trade-off behaviour and conditioned place avoidance show that the shock is eliciting a subtle and flexible response, but they don't show this response to be driven by nociceptive mechanisms:

"The main problem with electric shock, especially for aquatic animals, is that it non-specifically activates any electrically excitable cell, including non-neural ones (e.g. muscle tissue), meaning that assumed 'nociceptive behaviours' triggered by such stimuli may represent abnormal responses of the nervous system (or other systems, see Derby and Steullet, 2001), rather than reveal the workings of a nociceptive sensory system tuned to tissue damage by evolution (Puri and Faulkes, 2015)." (Diggles 2018, pp. 4-5) 
As far as I know, it is correct that, while we have evidence of trade-off behaviour and separate evidence of nociception in decapods, we don't have evidence that the trade-off behaviour is mediated by nociceptors. That said, this situation is not unique to decapods. It is common in studies of human and non-human pain to use electric shocks as a negative stimulus without specifically investigating whether the stimulus activates nociceptors. In other taxa, this is not considered a reason to discount subsequent aversive behaviour as potentially indicative of aversive conscious experience.

We should, of course, acknowledge that there is room for alternative explanations of the observed trade-off behaviour. For example, in the Appel and Elwood study on hermit crabs (Appel and Elwood 2009; Elwood and Appel 2009), it is possible that the shocks delivered inside Gibbula shells were more powerful than those of the same voltage delivered inside Littorina shells, coincidentally aligning with the shell preferences of the crabs. The shells differ in shape, and it's possible that the electrodes made closer contact with the crab in the Gibbula shell. This possibility is noted by Magee and Elwood (2016), so they can hardly be accused of dismissing alternative explanations.

The evidence here is not conclusive. No one should call this conclusive evidence of pain experience, and Elwood does not do this. It's appropriate that there should be robust scientific debate about these experiments, along with attempts at replication and attempts to gather more evidence. But, for the time being, we have to decide how to act on the information that we do have. Should we, or should we not, take precautionary measures to safeguard the welfare of these animals in the face of serious risks? My framework is an attempt to identify the key questions we need to answer:

(1) Do the experiments in question meet normal scientific standards?

(2) Do they provide evidence of a credible indicator of sentience?

Regarding the first question, all sides should be able to agree that debate on this question is important, and that there should be "no lowering of scientific standards with regard to the design, methodology, and replication of experiments, or the analysis and interpretation of data" (Diggles 2018, p. 13). But I see nothing to indicate that Elwood's experiments involve any lowering of scientific standards. They are sound experiments, even though the results are not conclusive.

Regarding the second question, I can see that a sceptic might argue that trade-off behaviour alone is not a credible indicator of sentience (in the narrow sense of subjective experience with an attractive or aversive quality) unless the trade-off behaviour can be shown to be mediated by nociceptive mechanisms. Showing that electric shocks do activate nociceptors seems like an important and achievable objective for further work.

The question of what is, or is not, a credible indicator of sentience is one that the animal sentience research community should decide collectively (Birch 2017a, p. 7). I hope that the target article and accompanying commentaries have helped to crystallize the issues, even though they do not resolve them. The important thing is that there should be a clear set of goalposts that are not moved in an ad hoc way as evidence accumulates. If it is agreed by the sceptics now that trade-off behaviour in response to stimuli independently shown to activate nociceptors is a credible indicator of sentience, then it should be agreed now that if electric shocks are shown to activate nociceptors, then this evidence plus the existing behavioural evidence would provide evidence of a credible indicator. In short, I encourage 
Diggles and other sceptics to tell us now what they would accept as a credible indicator of sentience.

If the answer is "yes" to questions (1) and (2), then we are justified in taking appropriate precautionary measures, and we can move on to debating the most appropriate measures to take. My proposed framework leaves plenty of options open, including the most conservative option of commissioning further research into decapod sentience as a matter of high funding priority, with a presumption in favour of protecting the order if no new evidence comes to light (Birch 2017b, p. 15). It seems to me that, if nothing else, sceptics about decapod sentience should at least be able to agree about the great importance of further research.

\subsection{Broader concerns about a precautionary approach}

Diggles raises some more general concerns that merit further discussion. One is that "if the precautionary principle is enacted too early, a paradoxical 'Catch-22' situation may arise in that restrictive animal ethics requirements may hinder or even prevent the high-quality studies needed to provide the data to solve unresolved scientific questions" (p. 13). The dilemma here is clear: more research into sentience in currently unprotected taxa is urgently needed - but wouldn't the precautionary extension of animal welfare protection to these taxa impede this research?

I suggest that bringing a taxon within the scope of animal welfare law is in fact likely to stimulate more research into its welfare needs. The case of cephalopods is instructive here. The inclusion of cephalopods within the scope of the $2010 \mathrm{EU}$ directive on the protection of animals used for scientific purposes has led to substantial interest in formulating detailed, evidence-based guidelines for safeguarding their welfare, leading to proposals such as that of Fiorito et al. (2015). It is true that new experiments aimed at understanding cephalopod welfare will need ethics approval, which might be a disincentive, but I hope the incentives created by the need for clear ethical guidelines outweigh that disincentive. There is a feedback loop here - extending the scope of animal welfare regulation influences the research that informs that regulation - but the feedback can be positive rather than negative.

A second concern is that:

"If the precautionary principle is used to justify inclusion of certain animal groups under welfare regulation, policymakers should be obliged to regularly review the scientific criteria used to justify such decisions, and/or include provision for 'sunset clauses' for the withdrawal of such taxa from protection if more robust scientific data becomes available at a later date which invalidates the preliminary results used to trigger the precautionary decision." (Diggles 2018, p. 13)

This suggestion is compatible with my proposals. Any precautionary measure should be proportionate to the threat, in the sense of being sufficient to mitigate the identified risk but not excessive (i.e., it should not do more than is necessary), and in the sense of being the most cost-effective of the available sufficient but non-excessive measures. An extension to the scope of animal welfare protection subject to renewal after a further review of the evidence after a specified period would be in keeping with the idea of proportionality. 
Acknowledgements: Thanks again to all the commentators, and particularly to Robert Elwood for his comments on a draft of this response. This work was supported by a Philip Leverhulme Prize from the Leverhulme Trust.

\section{References}

Allen, C. (2004) Animal pain. Noûs 38: 614-643.

Allen, C. (2013) Fish cognition and consciousness. Journal of Agricultural and Environmental Ethics 26: 25-39.

Appel, M., and Elwood, R. W. (2009) Motivational trade-offs and potential pain experience in hermit crabs. Applied Animal Behaviour Science 119: 120-124.

Birch, J. (2017a) Animal sentience and the precautionary principle. Animal Sentience 16(1).

Birch, J. (2017b) Refining the precautionary framework. Animal Sentience 16(20).

Birch, J. (2017c) Crabs and lobsters deserve protection from being cooked alive. Aeon, 3.

Birch, J. (2018) Degrees of sentience? Animal Sentience 21(11).

Bronfman, Z. Z., Ginsburg, S., and Jablonka, E. (2016) The evolutionary origins of consciousness: Suggesting a transition marker. Journal of Consciousness Studies 23: 7-34.

Carder, G. (2017) A preliminary investigation into the welfare of lobsters in the UK. Animal Sentience 16(19).

Clark, R. E., and Squire, L. H. (1998) Classical conditioning and brain systems: The role of awareness. Science 280: 77-81.

Derby, C. D., and Steullet, P. (2001) Why do animals have so many receptors? The role of multiple chemosensors in animal perception. Biological Bulletin 200: 211-215.

Diggles, B. (2018) Review of some scientific issues related to crustacean welfare. ICES Journal of Marine Science.

Dretske, F. I. (2006) Perception without awareness. In Gendler, T. S., and Hawthorne, J. (Eds.), Perceptual Experience. Oxford: Oxford University Press, pp. 147-180.

Dylla, K. V., Galili, D. S., Szyszka, P., and Lüdke, A. (2013) Trace conditioning in insects-keep the trace! Frontiers in Physiology 4: 67.

Elwood, R. W. (2012) Evidence for pain in decapod crustaceans. Animal Welfare 21: 23-27.

Elwood, R. W. (2018) Assessing negative and positive evidence for animal pain. Animal Sentience 16(21).

Elwood, R. W., and Appel, M. (2009) Pain experience in hermit crabs? Animal Behaviour 77: 1243-1246.

Fiorito, G., Affuso, A., Basil, J., Cole, A., de Girolamo, P., D’Angelo, L., Dickel, L., Gestal, C., Grasso, F., Kuba, M., Mark, F., Melillo, D., Osorio, D., Perkins, K., Ponte, G., Shashar, N., Smith, D., Smith, J., and Andrews, P. L. R. (2015) Guidelines for the care and welfare of cephalopods in research - A consensus based on an initiative by CephRes, FELASA and the Boyd Group. Laboratory Animals 49: 1-90.

Ha, H., Hendricks, M., Shen, Y., Gabel, C. V., Fang-Yen, C., Qin, Y., Colón-Ramos, D., Shen, K., Samuel, A. D. T., and Zhang, Y. (2010) Functional organization of a neural network for aversive olfactory learning in Caenorhabditis elegans. Neuron 68: 1173-1186.

Jeffreys, H. (1961). Theory of Probability (3rd edition). Oxford: Oxford University Press. 
Magee, B., and Elwood, R. W. (2016) Trade-offs between predator avoidance and electric shock avoidance in hermit crabs demonstrate a non-reflexive response to noxious stimuli consistent with prediction of pain. Behavioural Processes 130: 31-35.

Nordgreen, J., Janczak, A. M., Hovland, A. L., Ranheim, B., and Horsberg, T. E. (2010) Trace classical conditioning in rainbow trout (Oncorhynchus mykiss): What do they learn? Animal Cognition 13: 303-309.

Puri, S., and Faulkes, Z. (2015) Can crayfish take the heat? Procambarus clarkii show nociceptive behaviour to high temperature stimuli, but not low temperature or chemical stimuli. Biology Open 4: 441-448.

Roth, B., and Grismbø, E. (2016) Electrical stunning of edible crabs (Cancer pagurus): From single experiments to commercial practice. Animal Welfare 25: 489-497.

Seth, A. K., and Dienes, Z. (2017) The value of Bayesian statistics for assessing credible evidence of animal sentience. Animal Sentience 16(22).

Szyszka, P., Demmler, C., Oemisch, M., Sommer, L., Biergans, S., Birnbach, B., Silbering, A. F., and Galizia, C. G. (2011) Mind the gap: Olfactory trace conditioning in honeybees. The Journal of Neuroscience 31: 7229-7239.

Wagenmakers, J., Wetzels, R., Borsboom, D., and van der Maas, H. L. J. (2011) Why psychologists must change the way they analyze their data: The case of psi: Comment on Bem (2011). Journal of Personality and Social Psychology 100: 426-432. 